\title{
STUDY OF GENITAL TUBERCULOSIS IN INFERTILE WOMEN
}

\author{
Shrikant Ohri' ${ }^{1}$ Sanjay Kumar Patil2, Anjali Patil ${ }^{3}$, Yamini Patil ${ }^{4}$, N. S. Kshirsagar 5 \\ ${ }_{13}^{\text {rd }}$ Year Post Graduate Resident, Department of Obstetrics and Gynaecology, Krishna Institute of Medical Sciences, Karad. \\ 2 Professor, Department of Obstetrics and Gynaecology, Krishna Institute of Medical Sciences, Karad. \\ ${ }^{3}$ Assistant Professor, Department of Obstetrics and Gynaecology, Krishna Institute of Medical Sciences, Karad. \\ ${ }^{4}$ Associate Professor, Department of Obstetrics and Gynaecology, Krishna Institute of Medical Sciences, Karad. \\ 5Professor, Department of Obstetrics and Gynaecology, Krishna Institute of Medical Sciences, Karad.
}

\section{ABSTRACT}

\section{AIM}

To determine the incidence of female Genital Tuberculosis (GTB) and to analyse clinicopathological features for GTB and comparison of Polymerase Chain Reaction (PCR), Acid Fast Bacillus (AFB) staining and Histopathology (HPR).

\section{STUDY SETTING}

A prospective study conducted on 50 infertile patients in the Department of Obstetrics and Gynaecology at Krishna Hospital, Karad, for a period of 2 years between December 2013 and December 2015.

\section{METHODS}

Patients were investigated for the presence of Mycobacterium Tuberculosis (MTB) on samples collected by endometrial curettage by PCR, AFB and HPR. Additional tests like Hysterosalpingography (HSG) Laparoscopic chromopertubation and hysteroscopy were performed if not done earlier.

\section{RESULT}

PCR demonstrated MTB DNA in 9 patients, and 2 were positive with AFB and HPR. Within positive patients HSG findings were suggestive of TB in 3 cases and laparoscopy in 5 cases and hysteroscopy in 4 cases. Two MTB PCR positive patients conceived spontaneously after 6 months of anti-tubercular treatment.

\section{CONCLUSION}

Genital tuberculosis is a diagnostic challenge if untreated it is chronic, progressive and destructive disease. Early diagnosis is crucial because once the infection damages the tubes, reverting tubal patency is very difficult. Molecular tests like DNA PCR have enabled us to detect the organism in its latent stage and initiation of treatment early in the disease can prevent many irreversible changes in the female genital tract.

\section{KEYWORDS}

Anti-Tubercular Treatment, Hysterosalpingography, Tuberculosis, Genital Tuberculosis.

HOW TO CITE THIS ARTICLE: Ohri S, Patil SK, Patil A, et al. Study of genital tuberculosis in infertile women. J. Evolution Med. Dent. Sci. 2016;5(50):3195-3198, DOI: 10.14260/jemds/2016/741

\section{INTRODUCTION \\ Tuberculosis is a disease of antiquity. Evidence of tuberculosis has been demonstrated in the Neolithic and ancient Egyptian remains. Skeletal remains of prehistoric humans dating back to $8000 \mathrm{BC}$ found in Germany have shown evidence of the disease. Ancient Hindu and Chinese scripts also have documented the existence of this disease.[1] \\ Tuberculosis remains a worldwide public health problem despite the fact that the causative organism was discovered more than a hundred years ago and a vaccine and highly effective drugs are available making tuberculosis both a preventable and curable disease.[2] The problem of tuberculosis is acute in developing countries, which account for $95 \%$ of cases, the South and the East Asian region accounting for $40 \%$ of them. ${ }^{[3]}$}

Financial or Other, Competing Interest: None

Submission 30-03-2016, Peer Review 31-05-2016,

Acceptance 07-06-2016, Published 22-06-2016.

Corresponding Author:

Dr. Shrikant Ohri,

New Life Hospital, 70,

Gandhi Nagar Sigra,

Varanasi-221010

Uttar Pradesh.

E-mail: shrikant_391@hotmail.com

DOI: $10.14260 /$ jemds/2016/741
Although the pulmonary form is the most commonly encountered, it is all too frequently forgotten that tuberculosis is a disseminated disease. Genital tract disease usually originates from haematogenous dissemination from a focus elsewhere in the body.[4] The fallopian tubes like their embryological male homologue, the epididymis are the initial sites of pelvic involvement following haematogenous dissemination of the bacilli. ${ }^{[5]}$ When tuberculosis affects the genital organs, it leads to devastating effects resulting in infertility; and less commonly as menstrual disturbances and pelvic paid syndromes. The incidence of tuberculosis is estimated to be between $5.7-19 \%$ of all infertile women, the incidence being higher in cases evaluated for infertility due to tubal causes.

The prevalence of infertility is about $10-20 \%$ among couples (With somewhat equal prevalence among men and women). There are many factors that can affect female fertility. Some, such as tubal or age factor and others.

Female Genital Tuberculosis (FGTB) is still a major cause of infertility in India in spite of the availability of specific therapy. The prevalence of FGTB in infertility clinics shows marked variations in different countries ranging between 15 and $25 \%$ in $80-90 \%$ of cases, FGTB affects young women between 18 and 38 years of age and is an important cause of infertility. 
Genital Tuberculosis (GTB) predominantly affects individuals below 40 years of age and peak age frequency ranges between 21 and 30 years of age.

\section{MATERIAL AND METHODS}

A prospective study.

\section{Study Population}

50 outdoor patients who came for the treatment of infertility in the Department of Obstetrics and Gynaecology at Krishna Hospital, Karad.

\section{Duration}

2 years from December 2013 to December 2015.

Aim of our study was to see the incidence of GTB in infertility to analyse the clinicopathological features of GTB positive patients and to compare different diagnostic method like PCR, AFB staining and histopathology.

Previous records of investigations, treatment, coital history, history of recurrent vaginitis, menstrual pattern (Cycle duration and amount of flow, i.e. oligomenorrhoea, menorrhagia) and history of dysmenorrhea and dyspareunia was noted.

Preliminary tests were done including semen analysis, hysterosalpingography and a subsequent diagnostic hysterolaparoscopy if not done previously.

\section{Sample Collection}

Three endometrial samples were collected by Dilatation and Curettage at the time of hysterolaparoscopy.

$1^{\text {st }}$ endometrial tissue was placed in formalin preservative and was sent for histopathology examination and the other two in normal saline and were sent for AFB staining and Polymerase Chain Reaction.

\section{Treatment}

All those with positive PCR were counselled and treated with anti-tubercular drugs. They were subjected to four drug regime (HRZE) INH $300 \mathrm{mg}$, Rifampicin 450-600 mg, Pyrizinamide 1200-1500 mg, Ethambutol 800-1200 mg for 2 months followed by same doses of INH and Rifampicin for 4 months.

\begin{tabular}{|c|c|c|}
\hline Parameter & $\begin{array}{c}\text { Total } \\
\text { No. }\end{array}$ & $\begin{array}{c}\text { TB } \\
\text { Positive }\end{array}$ \\
\hline \multicolumn{3}{|l|}{ Age } \\
\hline$<21$ & 3 & 0 \\
\hline $22-25$ & 32 & 3 \\
\hline $26-29$ & 5 & 1 \\
\hline $30-33$ & 10 & 5 \\
\hline \multicolumn{3}{|l|}{ Socioeconomic Class } \\
\hline Lower & 4 & 3 \\
\hline Middle & 41 & 5 \\
\hline High & 5 & 1 \\
\hline \multicolumn{3}{|l|}{ Menstrual Flow Pattern } \\
\hline Hypomenorrhoea/oligomenorrhoea & 15 & 5 \\
\hline Polymenorrhagia & 5 & 1 \\
\hline Normal & 30 & 3 \\
\hline Total & 50 & 9 \\
\hline \multicolumn{3}{|l|}{ Symptoms } \\
\hline Fever & 8 & 4 \\
\hline Weight Loss & 10 & 3 \\
\hline Chronic Pelvic pain & 12 & 3 \\
\hline Dysmenorrhoea & 12 & 4 \\
\hline
\end{tabular}

\section{RESULT}

Among the 50 patients of infertility, 9 were diagnosed to be suffering from FGTB on the basis of PCR alone and within these 9 two were positive with HPR and AFB staining.

8 were of primary infertility and 1 was a case of secondary infertility. Duration of infertility was less than 5 years in 5 positive cases and 5 cases were in the age group of 30 to 33 years. Prevalent in middle and lower socioeconomic strata, i.e. 8 cases.

Oligomenorrhoea and dysmenorrhoea was seen in 5 cases. Within positive patients HSG was suggestive of TB in 3 cases and laparoscopy was suggestive in 5 cases and hysteroscopy in 4 cases.

Treatment to all affected individual was given. After a followup of 6 months, spontaneous pregnancies were achieved in 2 women, after initiation of Anti-Tubercular Treatment.

\begin{tabular}{|l|c|}
\hline \multicolumn{2}{|c|}{ Findings on HSG } \\
\hline Uterine Findings & No. \\
\hline Findings & 6 \\
\hline Normal & 1 \\
\hline Intravasation of Contrast & 2 \\
\hline Irregular Cavity & 6 \\
\hline Tubal Findings & 3 \\
\hline Bilateral Free Spill & 4 \\
\hline Bilateral No Spill & 4 \\
\hline Laparoscopic Chromopertubation & 1 \\
\hline Free spill & 5 \\
\hline No spill & 1 \\
\hline Loculated tubes with spill & 2 \\
\hline Uterine Cavity on Hysteroscopy & 1 \\
\hline Normal Study & \\
\hline Tubercles & \\
\hline $\begin{array}{l}\text { Mild-to-moderate Intra-Uterine Adhesions and } \\
\text { fibrosis }\end{array}$ & \\
\hline Severe adhesion (distorted cavity) & \\
\hline \multicolumn{2}{|c|}{ Findings of Patients with Genital Tuberculosis } \\
\hline
\end{tabular}

\section{DISCUSSION}

In this study, 50 women with infertility were taken. Out of them 9 were diagnosed to have GTB. The high incidence in the study population correlates well with studies conducted among infertile women in developing countries.[6] GTB was responsible for $44 \%$ of cases of tubal blocks in the study population.

Among the positive cases $88 \%$ were cases of primary infertility. Schaefer.[7] estimated that $85 \%$ of cases of genital tuberculosis had primary infertility. Jindal.[8] reported $68 \%$ incidence of primary infertility.

In studies covering women of all age groups, Schaefer.[7] reported that $68 \%$ of their patients with genital tuberculosis were in the young age group, Nagpal.[9] mentions a $74 \%$ incidence in the 21-30 years' age group. Thus genital tuberculosis is predominantly a disease affecting women in their fertile years.

This is justified as after the puberty the blood supply to the pelvic organs increases and as a result more bacilli could reach this site and infect the reproductive organ. According to Jha $\mathrm{A}$ et al and Gungorduk K genital TB is rare after menopause.[10,11] Apart from infertility, the other major presenting complaints described include abnormal bleeding, pelvic pain and menstrual irregularity. In a study done by Singh $\mathrm{N}$ et al, 
revealed menstrual abnormalities in $30 \%$ patients in which menstrual abnormality were in the form of hypomenorrhoea and secondary amenorrhoea.[12]

In our study, 6 (66\%) out of the 9 women of tuberculosis had menstrual abnormalities with hypomenorrhoea in 5 cases (55\%).

Schaefer.[7] considers pelvic pain, an important symptom of pelvic tuberculosis occurring in about $50 \%$ of patients. Simon et al[13] recorded that pelvic pain was the initial symptom in $45 \%$ of their patients, but it was usually mild and chronic in nature. Morris et al[14], however, considers that patients who present with infertility rarely have pelvic or abdominal pain or other symptoms.

Three of our patients with tuberculosis complained about significant pelvic pain. Constitutional symptoms such as fever in 4 (44\%), weight loss in 3 (33\%) were reported among the positive cases.

An analysis of the socio-economic background reveals that genital tuberculosis unlike its more widespread pulmonary counterpart tends to affect both the affluent and the impoverished.

Two patients (22\%) had a previous history of tuberculosis. Schaefer.[15] mentions an incidence of pulmonary tuberculosis in $20 \%$ cases of women with genital tuberculosis.

Only 6 out of the 9 patients with tuberculosis showed patent tubes on hysterosalpingography. Bilateral tubal blocks were common in 3 (33\%), especially cornual blocks.

A study done by J B Sharma et al among 40 women diagnosed with tuberculosis $11(27.5 \%)$ had abnormal hysterosalpingography finding, which is consistent with my study. ${ }^{[16]}$ Nagpal. ${ }^{[9]}$ records a 30\% incidence of bilateral tubal blocks.

Diagnostic laparo-hysteroscopy was particularly useful to confirm cases suspected on hysterosalpingography. Presence of intrauterine adhesions on hysteroscopy, presence of adhesions on the uterine surface, in the cul-de-sac and on the hepatic surface; thickening of tubes; presence of hydrosalpinx; presence of tubercles in the peritoneal cavity and on the omental surface during laparoscopy provides clues to the diagnosis, which can be confirmed by laboratory methods before initiating therapy. Similar findings are mentioned by Charles D.[4] Marana R.[17] Avan BI.[18] Raut VS.[19] and Yang Y.[20]

Confirmation of diagnosis was done by laboratory methods; 2 cases showed the characteristic granulomas on histopathological examination, 2 stained positive for acid-fast bacilli and 9 specimens were positive by PCR Jindal.[8] reported endometrial involvement in $84 \%$ cases, but none of them revealed acid-fast bacilli on staining.

Rozati et al observed PCR to be positive in $43 \%$ suspected cases of female genital tract tuberculosis in contrast to $5.2 \%$, $7.8 \%$ and $11.5 \%$ detection rate with AFB staining, culture and HPR respectively.[21]

The pregnancy rates reported in a few studies in female genital tuberculosis cases with positive PCR ranging from $19.35 \%$ to $59.8 \%$. Suman Puri and Bhavana Bansal investigated 60 patients for genital tuberculosis by PCR technique 28 patients were positive $(46.6 \%)$ and the pregnancy rate was $19.35 \% .{ }^{[22]}$ a study by Vidushi, Alkakriplani and others on genital tuberculosis in 196 cases fertility outcome after anti-tubercular treatment was 31\%.[23] V. N. Jindal, S. Verma and Y Bala in their study of 443 cases on fertility outcomes following anti-tubercular treatment showed overall pregnancy rate of $59.8 \%$.[24]

In our study treatment to all affected individual was given. Spontaneous pregnancies was achieved in 2 out of 9 women, after 6 months of anti-tubercular treatment.

In highly prevalent country for tuberculosis as in India, Tuberculosis should be considered while treating infertile couples. Infertility can be improved by early screening, diagnosing and then prompt treatment.

\section{CONCLUSION}

- Genital tuberculosis is a diagnostic challenge if untreated it is chronic, progressive and destructive disease.

- Early diagnosis is crucial, because once the infection has damaged the tubes reverting tubal patency is very difficult.

- Molecular tests like DNA PCR have enabled us to detect the organism in its latent stage, and initiation of treatment early in the disease can prevent many irreversible changes in the female genital tract.

- Further studies are required to understand the disease in its latency and evolve treatment algorithms.

- A better awareness and understanding of the epidemiology, the manifestations of the disease and the scope for diagnosis and treatment will go a long way in reducing the morbidity associated with this elusive disease.

\section{REFERENCES}

1. Dutt AK, Stead WW. Epidemiology and host factors. In: Schlossberg D, editor. Tuberculosis and non-tubercular mycobacterial infections. $4^{\text {th }}$ ed. Philadelphia. WB Saunders and Co. 1999:3-15.

2. Park K. Epidemiology of communicable diseases. In: Park's Textbook of Preventive and Social Medicine. 23rd ed. Bhanot B Publishers 2015:175-202.

3. WHO factshreet no 104 aug.2002. [online] WHO website. Available from

http://www.who.int/mediacentre/factsheets/fs104 /en/

4. Charles D. Tuberculosis of the female genital tract. In: Charles D. editor. Infections in obstetrics and gynaecology. $1^{\text {st }}$ ed. WB Saunders and Co 1980:243-52.

5. Daly JW, Monif GRG. Mycobacteria. In: Giles RG, Monif GRG, editors. Infectious diseases in obstetrics and gynaecology. $2^{\text {nd }}$ ed. Harper \& Row, Publishers, Philadelphia 301-16.

6. Bapna N, Swarankar M. Genital tuberculosis and its consequences on subsequent fertility. Int Jour Gynaecol Obstet 2005;55:534-7.

7. Rao PS, Kotian M, Rao K, et al. Bacterial flora of the endometrium in infertile women from Manipal. Indian J Pathol Microbiol 1992;35(4):357-61.

8. Jindal UN, Bala Y, Sodhi S, et al. Female genital tuberculosis: early diagnosis by laparoscopy and endometrial polymerase chain reaction. International Union against Tuberculosis and Lung Disease 2010;14(12):1629-34.

9. Nagpal M, Pal D. Genital tuberculosis-a diagnostic dilemma in OPD patients. J Obstet Gynaecol India 2001;51(6):127-31. 
10. Crochet JR, Hawkins KC, Holland DP, et al. Diagnosis of pelvic tuberculosis in a patient with tubal infertility. Fertility and Sterility 2011;95(1):289.e17-e20.

11. Gungorduk K, Ulker V, Sahbaz A, et al. Postmenopausal tuberculosis simulating disseminated ovarian carcinoma with elevated CA-125 level: report of two cases. Abdom Imaging 2002;27:465-70.

12. Singh N, Sumana G, Mittal S. Genital tuberculosis: a leading cause for infertility in women seeking assisted conception in north India. Arch Gynaecol Obstet 2008;278(4):325-7.

13. Simon HB, Weinstein AJ, Pasternak MS, et al. Genitourinary tuberculosis: clinical features in a general hospital population. Am J Med 1977;63(3):410-20.

14. Morris CA, Boxall FN, Clayton HR. Genital tuberculosis in sub-fertile women. J Med Microbiol 1970;3(1):85-90.

15. Saracoglu OF, Mungan T, Tanzer F. Pelvic tuberculosis. Int Jour Gynaecol Obstet 1992;37(2):115-20.

16. Sharma JB, Roy KK, Pushparaj M, et al. Laparoscopic findings in female genital tuberculosis. Arch Gynaecol Obstet 2008;278(4):359-64.

17. Marana R, Muzii L, Lucisano A, et al. Incidence of genital tuberculosis in infertile patients submitted to diagnostic laparoscopy: recent experience in an Italian university hospital. Int J Fertil 1991;36(2):104-7.
18. Avan BI, Fatmi Z, Rashid S. Comparison of clinical and laparoscopic features of infertile women suffering from genital tuberculosis (TB) or pelvic inflammatory disease (PID) or endometriosis. JPMA 2001;51(11):393-9.

19. Raut VS, Mahashur AA, Sheth SS. The Mantoux test in the diagnosis of genital tuberculosis in women. Intl Jour Gynaecol Obstet 2001;72(2):165-9.

20. Yang Y, Hao M, Zhu Y. Laparoscopic diagnosis of tubal infertility and fallopian tube lesions. Zhonghua Fu Chan Ke Za Zhi 1996;31(6):327-9.

21. Rozati R, Sreenivsagar R, Rajeshwari CN. Evaluation of women with infertility and genital tuberculosis. J Obstet Gynaecol Ind 2006;56(5):423-6.

22. Puri S, Bansal B. Diagnostic value of polymerase chain reaction in female tuberculosis leading to infertility and conception rate after ATT. JK Sciences 2009;11(1).

23. Kulshrestha V, Kriplani A, Agrawal N, et al. Genital tuberculosis among infertile women and fertility outcome after antitubercular therapy. International Journal of Gynaecology Obstetrics 2011;113(3):229-34.

24. Jindal UN, Verma S, Bala Y. Favourable infertility outcomes following antitubercular treatment prescribed on sole basis of a positive polymerase chain reaction test for endometrial tuberculosis. Human Reproduction 2012;27(5):1368-74. 